\title{
A GIS-based model to estimate flood consequences and the degree of accessibility and operability of strategic emergency response structures in urban areas
}

\author{
R. Albano ${ }^{1}$, A. Sole ${ }^{1}$, J. Adamowski ${ }^{2}$, and L. Mancusi ${ }^{3}$ \\ ${ }^{1}$ School of Engineering, University of Basilicata, Potenza, Italy \\ ${ }^{2}$ Bioresource Department, McGill University, Montreal, Canada \\ ${ }^{3}$ Sustainable Development and Energy Resources Department, Research on Energy Systems SpA, Milano, Italy
}

Correspondence to: R. Albano (albano.raffaele@tiscali.it)

Received: 27 February 2014 - Published in Nat. Hazards Earth Syst. Sci. Discuss.: 8 April 2014

Revised: 6 September 2014 - Accepted: 26 September 2014 - Published: 4 November 2014

\begin{abstract}
Efficient decision-making regarding flood risk reduction has become a priority for authorities and stakeholders in many European countries. Risk analysis methods and techniques are a useful tool for evaluating costs and benefits of possible interventions. Within this context, a methodology to estimate flood consequences was developed in this paper that is based on GIS, and integrated with a model that estimates the degree of accessibility and operability of strategic emergency response structures in an urban area. The majority of the currently available approaches do not properly analyse road network connections and dependencies within systems, and as such a loss of roads could cause significant damages and problems to emergency services in cases of flooding. The proposed model is unique in that it provides a maximumimpact estimation of flood consequences on the basis of the operability of the strategic emergency structures in an urban area, their accessibility, and connection within the urban system of a city (i.e. connection between aid centres and buildings at risk), in the emergency phase. The results of a case study in the Puglia region in southern Italy are described to illustrate the practical applications of this newly proposed approach. The main advantage of the proposed approach is that it allows for defining a hierarchy between different infrastructure in the urban area through the identification of particular components whose operation and efficiency are critical for emergency management. This information can be used by decision-makers to prioritize risk reduction interventions in flood emergencies in urban areas, given limited financial resources.
\end{abstract}

\section{Introduction}

Urban flooding is a serious and growing challenge. Against the backdrop of demographic growth, urbanization trends and climate change, the causes of floods are shifting and their impacts are accelerating (Jha et al., 2012). Between 1975 and 2002, floods due to drainage problems, flash, and river floods accounted for $9 \%$ of all deaths from natural disasters, with about 175000 fatalities worldwide and more than 2.2 billion people affected (Jonkman et al., 2005). From 2000 to 2006, water-related disasters killed more than 290000 people, affected more than 1.5 billion people, and inflicted more than USD 422 billion in damage (Adikati and Yoshitani, 2009). In light of this, there has been increased emphasis on new policies for increasing resilience to flooding (Djordjević et al., 2011), "preparing for floods" (ODPM, 2002), "making space for water" (Defra, 2004), and "living with risk" (UN/ISDR, 2004). This emphasis reflects in part the perception that a risk management paradigm is more complex than a more traditional standard-based approach as it involves "whole systems" and "whole life" thinking. However, this is its main strength and a prerequisite for more integrated and informed decision-making in the face of flood emergencies (Sayers at al., 2013). For example, in the Netherlands, seeking to provide "room for the river", scientists, policy-makers, and stakeholders have focused their attention on warning and evacuation systems, improvements in maintenance standards, and a decision-making process that reflects greater attention to economic efficiencies (Sayers at al., 2013). Flood forecasting, warning, emergency management, 
and other non-structural measures are increasingly being seen as critical for reducing flood consequences. As part of this, there is a need to refine methods to estimate flood risk and consequences, with particular attention on emergency management.

The Hyogo Framework for Action 2005-2015 (ISDR, 2004) highlights the central role of emergency planning in ensuring that a flood event does not become a flood disaster.

The internationally accepted and most common flood damage models (FLEMO model (Apel et al., 2009; Vorogushyn et al., 2012); HAZUS-MH (FEMA, 2003; Scawthorn, 2006); Damage Scanner Model (Klijn et al., 2007); Multi-Coloured Manual (Penning-Rowsell et al., 2005)) place economic values on flood risk in order to help planners in the estimation of the benefits of flood protection measures in terms of prevented flood damage. The latter approach does not take into account the dynamic nature of the urban system, with its interconnections and relationships among elements, and hence the performance of strategic structures and infrastructure in the case of emergency. Hence, indirect damages in the field of emergency management are not considered in these currently available consequence-estimation models. For example, the inaccessibility of inundated roads during emergency management activities could cause indirect damage to the operability of strategic structures such as hospitals or fire stations.

Other studies have dealt with specific aspects of emergency management, as well as identification of safest access routes (Dalziell et al., 2011), or evaluations of the number of unassisted people (Taylor et al., 2006). These studies have provided useful contributions to the analysis of road accessibility (Franchlin et al., 2006) and reliability (Lhomme et al., 2013). However, these studies did not consider emergency management of the whole system (i.e. quantification of the contributions of each structure or infrastructure in the maintenance of the performance of the rescue, and also its degree of vulnerability). On the one hand, the latter papers have not estimated the degree of physical damage of road networks and buildings due to natural events. On the other hand, although these papers analysed the accessibility and operability of road networks, they did not consider their typology (main roads, local roads, etc.) or the contribution of strategic structures (hospitals, civil protection centres, etc.) and hotspots (industries, resorts, and hotels) in the system.

Menoni et al. (2002) attempted to evaluate the systemic vulnerability of an urban system by using a model to assess the vulnerability due to lifeline failures (i.e. road system, water system, gas system, power system, etc.) for earthquake events. They proposed a regional-scale model that concentrates on the assessment of the large number of indirect damages to define where to engage in more detailed studies on vulnerability analysis (i.e. the cities and towns most affected by indirect damages evaluated through the model). This study highlighted the need to quantify, through spatial analysis, the contribution of infrastructure (e.g. road net- works) and structures (hospitals, industries, schools, etc.) in a city system to support decision-making regarding the type and location of the mitigation interventions.

Pascale et al. (2010) and Sdao et al. (2013) focused on the estimation of dependences within an urban system in the case of floods and/or landslide events by studying the "systemic" vulnerability, in terms of physical damage and functional relationship between operative centres and industries at risk or roads and private buildings at risk, etc., due to landslide or flood events. However, they did not analyse the spatial accessibility and operability relationships within the urban system based on the path connections and analysis, which is very important during the emergency phase of a flood event (i.e. during and immediately after a flood).

The proposed study overcomes the limitations of the approaches and models discussed above by integrating the concepts and methods of the previously mentioned studies, based on an accessibility and reliability analysis of the road network, within a systemic flood impact estimation. The proposed methodology couples the flow approach (Dalziell et al., 2001; Franchlin et al., 2006), based on flow and functionality of paths (i.e. comparison between the flow during normal working conditions and under disruption), with an approach based on topology (Lhomme et al., 2013) that considers structural analysis (i.e. it considers the number of alternative paths to the disruptions of one or several paths). In addition, the impact of road networks and dependencies between hotspots, i.e. buildings at risk (schools, private building, industries, etc.), and strategic structures, i.e. rescue centres (hospitals, fire stations, etc.), are estimated with a spatial analysis approach based on flows and topologies in order to evaluate the indirect impacts to the system during the emergency phase. Finally, the latter accessibility and operability model is integrated with a consequence-estimation model for urban areas based on the main concepts that drive the internationally used flood-consequence-estimation methods that were previously cited in order to evaluate the maximum impact of a chosen flood event in terms of direct and indirect damages only during the emergency phases of a flood event. The proposed model does not aim to estimate the entire wide range of indirect impacts that may have effects on time scales of months and years, i.e. macro-economic effects or longterm barriers to regional development (Merz et al., 2010). Instead, the model focuses on how the impact of a flood hazard on individual elements of strategic infrastructure or single nodes in network systems may influence the system as a whole (Meyer et al., 2013) in the emergency phase of a flood. Hence, the proposed model for consequence estimation in urban areas provides a quantitative evaluation of direct damage, to inform decision-making in terms of loss of life and structural and economic damages, which is useful in order to support an innovative methodology for investigating the relationships of spatial accessibility and functional/operability failure (i.e. the performance to guarantee victim assistance and rescue activities) in a complex urban system during the 


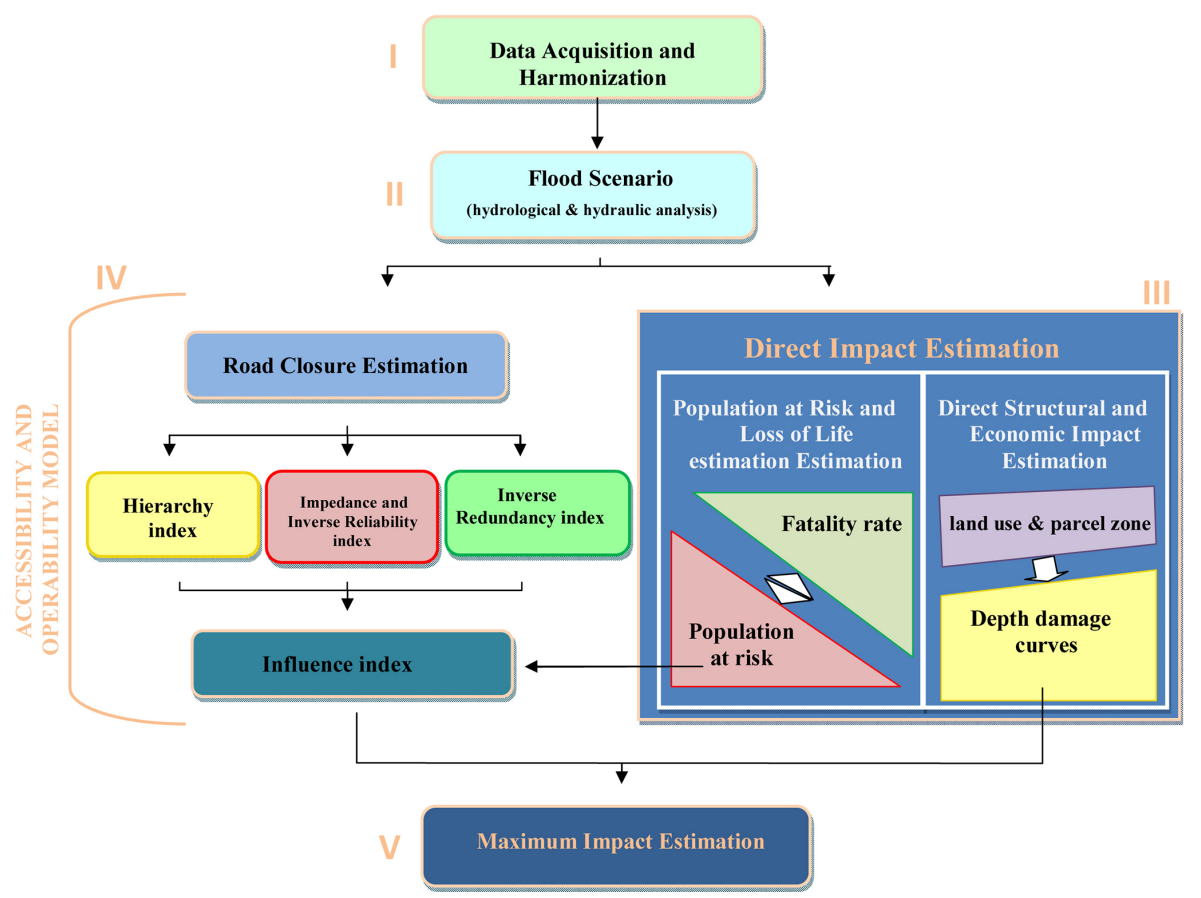

Figure 1. Phases of the proposed methodology.

emergency phase. Concurrently with the occurrence of physical and functional damage to urban areas, the operability of the strategic emergency structures, their accessibility, and connection within the city - or in general the urban area - is an important priority in emergency management.

The present framework, integrated in a geographic information system (GIS), aims to estimate the direct and indirect damage of a flood event in order to understand the strengths and fragilities of a particular urban area. The scope is to define a hierarchy between the various structures (hospitals, fire stations, town halls, schools, industries, etc.) and infrastructure (main roads, secondary and local roads, bridges, etc.) through the identification of those structures/infrastructure whose operation and effectiveness are critical in emergency management. The proposed model can aid in prioritizing the decisions on flood mitigation strategies that should be planned. This could support the maximization of the benefit of limited investments by selecting the highest-priority ones for emergency service. In Sect. 2, the overall GIS framework is outlined, in Sect. 3 the application and results of the proposed model on a real flood event are described, and overall conclusions are provided in Sect. 4.

\section{Overall framework}

This section describes the integration of a methodology that estimates the impact on accessibility and operability of strategic emergency response structures within an urban system, and a methodology for flood-consequence estimation in urban areas, with the aim of prioritizing actions for floodconsequence reduction (Fig. 1). Sections 2.1 and 2.2 describe the preliminary phases needed for the implementation of the methodology. Section 2.3 summarizes the proposed GIS methodology for the estimation of the consequences for an urban population, which can also be used to estimate the direct structural and economic damages for residential, commercial, and industrial buildings. Section 2.4 describes the proposed approach to explore the dependencies among the structures and infrastructure of a city during the emergency phase of a flood event (i.e. during or immediately after a flood), in terms of the accessibility of flood-prone areas and the operability of road networks for emergency service. Finally, in Sect. 2.5, this latter indirect-consequence estimation is coupled with direct-consequence estimation through a maximum-impact index.

\subsection{Data acquisition and harmonization}

The level of epistemic uncertainty in estimating potential damage by the model depends on available data (data collection, site visits, etc.). An analysis of the data considers land use distribution, data population census, digital elevation terrain models, and buildings and roads categorized on the basis of the function/typology (main roads, local roads, industries, resorts, hospitals, etc.). Therefore, the proposed approach requires the characterization of the system during the preliminary phases of the scheme in Fig. 1, i.e. phase I: input "data acquisition and harmonization" (data collection, site visits, etc.). 


\subsection{Definition of the flood scenario}

Phase II ("flood scenario: hydrological analysis and flood scenario evaluation") is concerned with the definition of a flood scenario, or flood scenarios, required to estimate the potential damages and/or in order to determinate the possible flood events. A flood scenario can be identified by a return period, a combination of loads that determine a failure scenario, the result of flood routing, etc. If the proposed model runs several times for different flood scenarios with different return times, it can relate probabilities of each flood event to potential consequences.

However, the evaluation of a flood scenario could be performed via a hydrological analysis, which could be essential for estimating flood probability of a scenario or of more scenarios, coupled with a flood simulation, that should preferably be conducted using a 2-D flood model (e.g. MIKE FLOOD developed by the Danish Hydraulic Institute, Telemac2D developed by the National Hydraulics and Environment Laboratory of the Research and Development Directorate of the French Electricity Board, and CCHE2D developed by the National Center for Computational Hydroscience and the School of Engineering of the University of Mississippi) that is likely to be data intensive but provides more detailed results in terms of velocity and water depth distribution. The latter parameters are essential to estimate the flood severity of the chosen scenario; flood severity is usually assigned using flood depth multiplied by average velocity value (DHS, 2011b).

\subsection{GIS direct-impact estimation}

This phase of the methodology is composed of two parts and provides two main results: the estimation of the loss of life and of the direct economic damages due the flood event.

\subsubsection{Population at risk and loss of life estimation}

During urban flooding events, consequences in terms of loss of life can be estimated as the combination of population exposed to the flood, i.e. population at risk and fatality rates (Escuder-Bueno et al., 2012) related to the characteristics of the flood (flood severity), evaluated in phase II. Indeed, the results of flood modelling and data from the population census are used. Geographic analyses are carried out using map algebra techniques implemented in a set of scripts tested and developed using the Python scripting language (http://www.python.org), the open-source Geospatial Data Abstraction Library (GDAL) (http://www.gdal.org), and the NumPy Python module (http://www.numpy.org). To combine multiple maps in map algebra, all data were required to be converted into grid format.

The outputs of the hydrodynamic model are processed to derive the information required for the analysis (flood wave arrival time, peak unit flow rate, etc.). Using GIS scripts, a
Table 1. Flood severity rating criteria (source: Department of Homeland Security (DHS), 2011b).

\begin{tabular}{ll}
\hline $\begin{array}{l}\text { Flood severity } \\
\text { rating }\end{array}$ & Rating criteria \\
\hline $\begin{array}{l}\text { Low } \\
\text { Medium }\end{array}$ & $\begin{array}{l}\text { DV less than } 5 \mathrm{~m}^{2} \mathrm{~s}^{-1} \\
\text { DV equal to or greater than } 5 \mathrm{~m}^{2} \mathrm{~s}^{-1} \\
\text { and less than } 15 \mathrm{~m}^{2} \mathrm{~s}^{-1}\end{array}$ \\
High & $\begin{array}{l}\text { DV equal to or greater than } 15 \mathrm{~m}^{2} \mathrm{~s}^{-1} \\
\text { combined with rate of rise at least } 3 \mathrm{~m} \text { in } 5 \mathrm{~min}\end{array}$ \\
\hline
\end{tabular}

flood wave arrival time (Twv), i.e. the time of occurrence of the flood wave, grid was obtained. In addition, the two components ( $x$ coordinate and $y$ coordinate) of the vector unit flow rate were combined to obtain the maximum peak unit flow rate values $\left(\mathrm{m}^{2} \mathrm{~s}^{-1}\right)$ (i.e. the flow discharge for each linear metre of cross section). These values, termed parameter DV, proposed by Graham (1999), are representative of the general level of destruction that would be caused by the flooding. The DV values are then categorized, as illustrated in Table 1 based on guidelines of DHS (2011b), widely used in the United States. The values are classified into ranges defined as low-, medium-, and high-severity zones that define the rating of the flood severity.

If the information on population is aggregated at the census area level, it could be hypothesized that it is distributed homogeneously within the vector polygon that represents the census areas. Hence, the vector polygons of the population census block are converted into grid format. By overlaying grid maps of flood with the grid of the population, it was possible to develop a map of population at risk (PAR).

Estimates of loss of life are obtained by multiplying the PAR with the fatality rate (fraction of people at risk projected to die from (severe) flood events). The fatality rates proposed in the SUFRI (Sustainable Strategies of Urban Flood Risk Management with non-structural measures to cope with the residual risk) project (Escuder-Bueno et al., 2012) are adopted in the model because it is based on a literature study and procedures that cover the loss-of-life estimation of historical flood events (e.g. Graham, 1999; DHS, 2011a, b; Penning-Rowsell et al., 2005), and it has been applied with good results in Italy (Escuder-Bueno at al., 2012). Ten categories were established by Escuder-Bueno et al. (2011) to estimate potential loss of life in urban areas in the case of river flooding. This classification of categories from low to high flood severity understanding, from $\mathrm{C} 1$ to $\mathrm{C} 10$, was developed based on levels of public education on flood risk, warning systems, risk communication, and coordination between emergency agencies and authorities (see Table 2). It defines a certain level of flood severity understanding for each category, linked to fatality rates and based on a compilation of historical data and existing reference values on loss of life (Graham, 1999; Escuder-Bueno et al., 2012). Consequently, 
Table 2. Fatality rates in the case of river flooding (Escuder-Bueno et al., 2012).

\begin{tabular}{|c|c|c|c|c|}
\hline \multirow{2}{*}{ ID } & \multirow{2}{*}{ Warning time $(\mathrm{h})$} & \multicolumn{3}{|c|}{ Flood severity } \\
\hline & & High & Medium & Low \\
\hline \multirow{6}{*}{$\mathrm{C} 1$} & 0 & 0.9 & 0.3 & 0.02 \\
\hline & 0.25 & 0.9 & 0.3 & 0.02 \\
\hline & 0.625 & 0.7 & 0.08 & 0.015 \\
\hline & 1 & 0.3 & 0.06 & 0.0006 \\
\hline & 1.5 & 0.3 & 0.0002 & 0.0002 \\
\hline & 24 & 0.08 & 0.0002 & 0.0001 \\
\hline \multirow{6}{*}{$\mathrm{C} 2$} & 0 & 0.9 & 0.3 & 0.02 \\
\hline & 0.25 & 0.9 & 0.3 & 0.02 \\
\hline & 0.625 & 0.675 & 0.075 & 0.014 \\
\hline & 1 & 0.3 & 0.055 & 0.00055 \\
\hline & 1.5 & 0.3 & 0.0002 & 0.0002 \\
\hline & 24 & 0.075 & 0.0002 & 0.0001 \\
\hline \multirow{6}{*}{$\mathrm{C} 3$} & 0 & 0.9 & 0.3 & 0.02 \\
\hline & 0.25 & 0.85 & 0.2 & 0.015 \\
\hline & 0.625 & 0.6 & 0.07 & 0.012 \\
\hline & 1 & 0.3 & 0.05 & 0.0005 \\
\hline & 1.5 & 0.3 & 0.0002 & 0.0002 \\
\hline & 24 & 0.075 & 0.0002 & 0.0001 \\
\hline \multirow{6}{*}{$\mathrm{C} 4$} & 0 & 0.9 & 0.3 & 0.02 \\
\hline & 0.25 & 0.75 & 0.15 & 0.01 \\
\hline & 0.625 & 0.5 & 0.04 & 0.007 \\
\hline & 1 & 0.3 & 0.03 & 0.0003 \\
\hline & 1.5 & 0.15 & 0.0002 & 0.0002 \\
\hline & 24 & 0.04 & 0.0002 & 0.0001 \\
\hline \multirow{6}{*}{ C5 } & 0 & 0.9 & 0.3 & 0.02 \\
\hline & 0.25 & 0.75 & 0.15 & 0.01 \\
\hline & 0.625 & 0.5 & 0.0375 & 0.0065 \\
\hline & 1 & 0.3 & 0.0275 & 0.000275 \\
\hline & 1.5 & 0.15 & 0.0002 & 0.0002 \\
\hline & 24 & 0.375 & 0.0002 & 0.0001 \\
\hline \multirow{6}{*}{ C6 } & 0 & 0.9 & 0.3 & 0.02 \\
\hline & 0.25 & 0.75 & 0.15 & 0.01 \\
\hline & 0.625 & 0.475 & 0.035 & 0.006 \\
\hline & 1 & 0.3 & 0.025 & 0.00025 \\
\hline & 1.5 & 0.15 & 0.0002 & 0.0002 \\
\hline & 24 & 0.035 & 0.0002 & 0.0001 \\
\hline \multirow{6}{*}{$\mathrm{C} 7$} & 0 & 0.9 & 0.3 & 0.02 \\
\hline & 0.25 & 0.65 & 0.1 & 0.0075 \\
\hline & 0.625 & 0.4 & 0.02 & 0.002 \\
\hline & 1 & 0.3 & 0.01 & 0.0002 \\
\hline & 1.5 & 0.1 & 0.0002 & 0.0002 \\
\hline & 24 & 0.02 & 0.0002 & 0.0001 \\
\hline \multirow{6}{*}{$\mathrm{C} 8$} & 0 & 0.9 & 0.3 & 0.02 \\
\hline & 0.25 & 0.55 & 0.06 & 0.006 \\
\hline & 0.625 & 0.35 & 0.01 & 0.0015 \\
\hline & 1 & 0.25 & 0.0050 & 0.0015 \\
\hline & 1.5 & 0.1 & 0.0002 & 0.00015 \\
\hline & 24 & 0.01 & 0.0002 & 0.0001 \\
\hline \multirow{6}{*}{ C9 } & 0 & 0.9 & 0.3 & 0.02 \\
\hline & 0.25 & 0.55 & 0.06 & 0.006 \\
\hline & 0.625 & 0.35 & 0.008 & 0.0015 \\
\hline & 1 & 0.2 & 0.004 & 0.000125 \\
\hline & 1.5 & 0.01 & 0.0002 & 0.0001 \\
\hline & 24 & 0.01 & 0.0002 & 0.0001 \\
\hline \multirow{6}{*}{$\mathrm{C} 10$} & 0 & 0.9 & 0.3 & 0.02 \\
\hline & 0.25 & 0.5 & 0.03 & 0.005 \\
\hline & 0.625 & 0.3 & 0.005 & 0.001 \\
\hline & 1 & 0.1 & 0.002 & 0.0001 \\
\hline & 1.5 & 0.01 & 0.0002 & 0.0001 \\
\hline & 24 & 0.01 & 0.0002 & 0.0001 \\
\hline
\end{tabular}

different fatality rates are considered for each category $(\mathrm{C} 1$ to $\mathrm{C} 10)$ depending on available warning times $(0-24 \mathrm{~h})$ and three flood severity levels described previously (Table 1 ). The warning time, which is a function of the Twv, at night is defined as a time period $15 \mathrm{~min}$ lower than the warning time during the day, such as in Escuder-Bueno et al. (2011). If there is no warning time or data are not available, the available warning time is estimated from the difference between the time of occurrence of the first-notice flow and the firstdamage flow, such as in Escuder-Bueno et al. (2011).

The final step for loss-of-life estimation relies on the combination of fatality rates and population at risk to obtain the number of potential fatalities for each flood scenario.

\subsubsection{Direct structural and economic impact estimation}

Methods and values of the parameters used in this section are drawn mostly from the report of the Department of Water Resources Division of Flood Management on Flood Rapid Assessment Model Development (F-RAM, 2008). The model is widely used in the evaluation of structural damage because it was evaluated in laboratories and real survey data from recent flood events in the United States.

The methods presented in this subsection (phase III of Fig. 1) are based on the use of depth-damage relationships that assign a percentage of damage from the resulting water depth during the flood.

An economic value of assets or land use was established, and economic losses were obtained from the destruction rate (e.g. percentage of damage) within the flooded area.

These curves are used for estimating the direct economic damage for residential, commercial, and industrial buildings. The input data consist of maps of land use and parcel zones of the study area.

The curves allow for the estimation of the damage to buildings and their contents and, when applied to different scenarios, allow for an effective comparison of the impact. The extent of damage to buildings and their contents is estimated from the flood depth by the application of a depthdamage curve associated with each occupancy type. Depth damage curves show the relationship between the depth of the flood relative to the first finished floor level of buildings and the damage caused to the structures and contents. Damage is typically expressed as a percentage of depreciated building replacement value. The adopted method measures the content damage directly as a percentage of structure value rather than using a content/ structure value ratio, i.e. the ratio between the unitary value of the content and the unitary value of the building structure, rather than formulating some specific content depth-damage curves that could be more difficult to estimate. To calculate damage, each structure must be assigned to a structure occupancy type. For each structure occupancy type an estimated replacement value, a structure depth-damage curve (Fig. 2) and a content depth-damage curve (Fig. 3) relationship must 
Structural Depth-Damage Curves as a Percentage of Depreciated Building Value for Depth of Flooding Above on the Ground Level

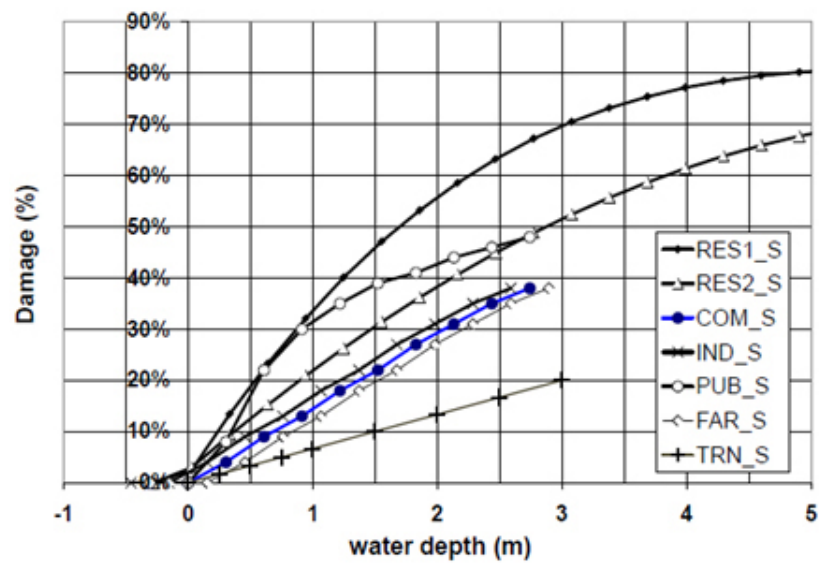

Figure 2. Structural depth-damage curves implemented in the model (source: Department of Water Resources Division of Flood Management, 2008).

Contents Depth-Damage Curves as a Percentage of Depreciated Building Value for Depth of Flooding Above on the Ground Level

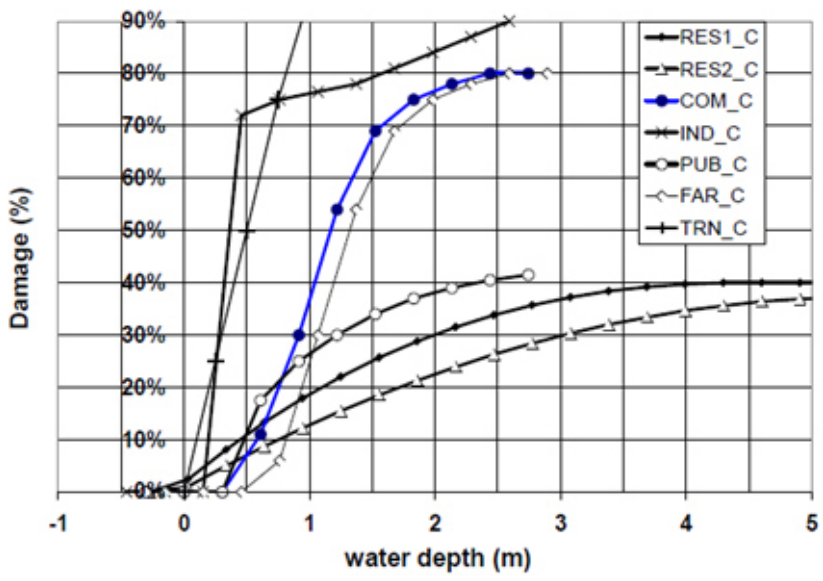

Figure 3. Content depth-damage curves implemented in the model (source: Department of Water Resources Division of Flood Management, 2008).

be defined. The depth-damage curves implemented in the model were obtained from the United States Army Corps of Engineers (USACE; Department of Water Resources Division of Flood Management, 2008). The methodology, here presented, could use other depth-damage curves that are more suitable for the area of interest; however, in the present model the USACE curves are implemented since they are suitable with the case study described in the next section, because they are more precautionary than the one proposed by Luino et al. (2003) for Italy. In assigning an occupancy type, taken usually from a city map at micro-scale, to each parcel, we chose values according to those shown in Table 3.
Table 3. Assigning occupancy type from zoning type.

\begin{tabular}{lll}
\hline Zoning type & No. of stories & $\begin{array}{l}\text { Occupancy } \\
\text { type }\end{array}$ \\
\hline $\begin{array}{l}\text { Commercial } \\
\begin{array}{l}\text { Industrial/wholesale/ } \\
\text { manufacturing }\end{array}\end{array}$ & Any & COM \\
Institutional/government & Any & IND \\
Office & 1 & PUB \\
Office & 2 or more & RES1 \\
Open space/recreation/ & & \\
agricultural & Any & FAR \\
Residential & 1 & RES1 \\
Residential & 2 or more & RES2 \\
Transport & Any & TRN \\
\hline
\end{tabular}

\subsection{GIS accessibility and operability model for emergency management}

This section describes how the infrastructural transport dependencies are estimated in the urban area during the emergency phases of a flood event (i.e. the performance of rescue activities taking into account the connections/paths between areas at risk and rescue centres such as hospitals and fire stations). In terms of emergency management, the failure of some part of the transport infrastructure would have the most serious effects on access to specific locations and overall system performance. The road closures due to flood waters, estimated on the basis of velocity and water depth values, could create damages and hence could alter the emergency travel operations from normal conditions. In this context, an analysis of the paths of the emergency travel activities could open the possibility to estimate the operability of the strategic emergency structures and highlight weaknesses (e.g. the most inaccessible area at risk or the strategic connectivity road that are most damaged). We focus on the emergency operations, and not on the evacuation of the people that could have been done in the pre-event phase of the flood event.

\subsubsection{Road closure estimation}

First, it is necessary to estimate road closures due to flood waters in order to estimate the potential inaccessible areas and inoperable roads (phase IV of Fig. 1). The possible road closures due to flood waters or large debris transport are estimated on the basis of literature studies that estimate a weight related to critical threshold values of hydraulic instability for idealized vehicles (Teo et al., 2012). If the vehicles on these streets are dragged by the water flow, the road is inaccessible. The envelope curves developed by Teo et al. (2012) consider three colour zones (i.e. green, yellow, and red), and the hydraulic stability for each idealized vehicle was easily identified by colour. The stable zone is shown in green (left zone), 


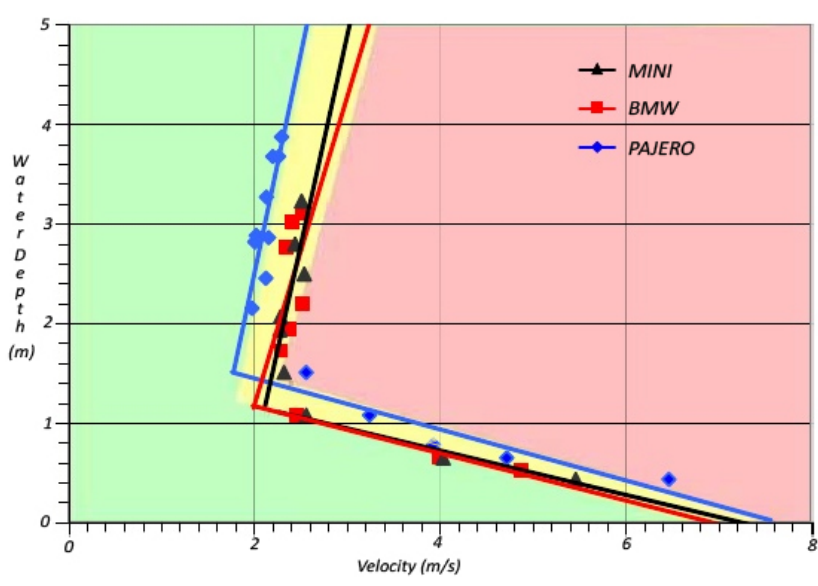

Figure 4. Critical threshold values of hydraulic instability for specific vehicles (taken from Teo et al., 2012).

the transition zone in yellow (central zone), and the unstable zone in red (right zone). All vehicles in the red zone of the graph are dragged by the water flow; hence they could block, for example, an emergency vehicle during rescue actions. The curves implemented in the model are used when incoming flow depths are lower than the vehicle height, shown in the lower part of the graph in Fig. 4. When the incoming flow depth is greater than the vehicle height, the roads are considered to be always inaccessible. This choice is justified by the possible presence of emergency vehicles that could work in worse conditions than cars (firefighter trucks, ambulances, small boats, etc.). As such, the methodology, on the one hand, aims to give more importance to closure of roads due to vehicle transport - which is a frequent phenomena in urban areas as highlighted in Albano et al. (2014), Gruntfest (2000), and Gruntfest and Ripps (2000) - and, on the other hand, aims to be precautionary and independent of the type of vehicles available in a specific scenario in the analysis.

\subsubsection{Accessibility and operability analysis of the urban system}

Emergency management systems operate their vehicles in different ways during an emergency such as a flood. For example, they might use local streets in order to take the shortest path to their destination since the lower speed limit of local streets may not apply to those emergency vehicles. As a result, the shortest path will provide them with the shortest time response. In this situation, a road closure due to a flood could alter the path that connects different elements in an urban area, such as the path between a hospital and a damaged school, thereby increasing the distance between them, which would result in a lower level of accessibility. Equation (1) is proposed to estimate the degree of inoperability of the arc $a_{i}$ that is a path $(i)$ within the system, i.e. the inverse (connectivity) reliability index, where the concept of reliability is introduced by Taylor et al. (2006) - see the central part of phase IV of Fig. 1:

$$
R_{a}=\sum_{P_{s i}=1}^{k}\left[\frac{\sum_{o=1}^{m}\left[\left(1-\frac{P_{s i, o}}{P_{\mathrm{e} i, o}}\right) \cdot \frac{P_{\mathrm{smax}, i}}{P_{s i, o}}\right]}{\sum_{o=1}^{m} \frac{P_{\mathrm{smax}, i}}{P_{s i, o}}}\right] / k,
$$

where $P_{\mathrm{s}}$ is the length of the generic standard path, and $P_{\mathrm{e}}$ is the length of the emergency path (i.e. the path that the aid vehicles have to travel due to the flood event). $P_{\text {Smax }}$ is the value of the longest standard path between all the standard paths that connects the aid centres with the building at risk. A path is defined as "standard" if the latter connects aid centres with buildings at risk in the normal functioning of system connections. These are defined as "emergency" paths if the system is affected by a flood event. Equation (1) is an average of the ratio $1-\left(P_{\mathrm{s}} / P_{\mathrm{e}}\right)$ weighted on the ratio $P_{\mathrm{s} \max } / P_{\mathrm{s}}$ in order to consider the whole accessibility system (i.e. all the shortest paths among the elements at risk and all the emergency centres in the system), normalized on $k$. The latter represents the number of times that the arch $a_{i}$ is crossed by the shortest paths $\left(P_{\mathrm{s}}\right)$ connecting the relations "origins/destinations", hereafter " $o / d$ ", where the origins $(o)$ are the core rescue buildings and the destinations are buildings at risk (i.e. private or public buildings, factories, etc.). If an emergency path does not exist, (i.e. the elements are completely isolated) this means that access to alternative services (such as hospitals and businesses) does not exist. The disruption costs to households, businesses, and communities can therefore be more critical for the whole system.

The inverse reliability index, estimated by Eq. (1), highlights the travel distance reliability of the path. Travel distance reliability considers the probability that a trip between an origin-destination pair (see Fig. 5) can be completed successfully via the shortest distance possible for the normal functioning of system connections; this is represented by the blue line in Fig. 5, and, for the case of a flood event, this is represented by the red line in Fig. 5. The ratio between $P_{\mathrm{S}}$ and $P_{\mathrm{e}}$ is weighted on the basis of the distance between $o$ and $d$ in order to relate this ratio to the urban system network dependencies in the emergency phase; the estimated value for each path is normalized on the basis of the multiple $o / d$ relationships because there can be more than one origin in the system (i.e. core rescue buildings).

Equation (1) is assigned to each arch $a_{i}$ that composes the shortest path $P_{\mathrm{s} i}$, but it is used in a modified version (see Eq. 2) also in order to estimate the degree of inaccessibility of an area that requires rescue (i.e. the impedance index, introduced by Taylor et al. (2006) but here modified in order to consider accessibility in the whole system for emergency service), assigning the estimated value to each building at risk 


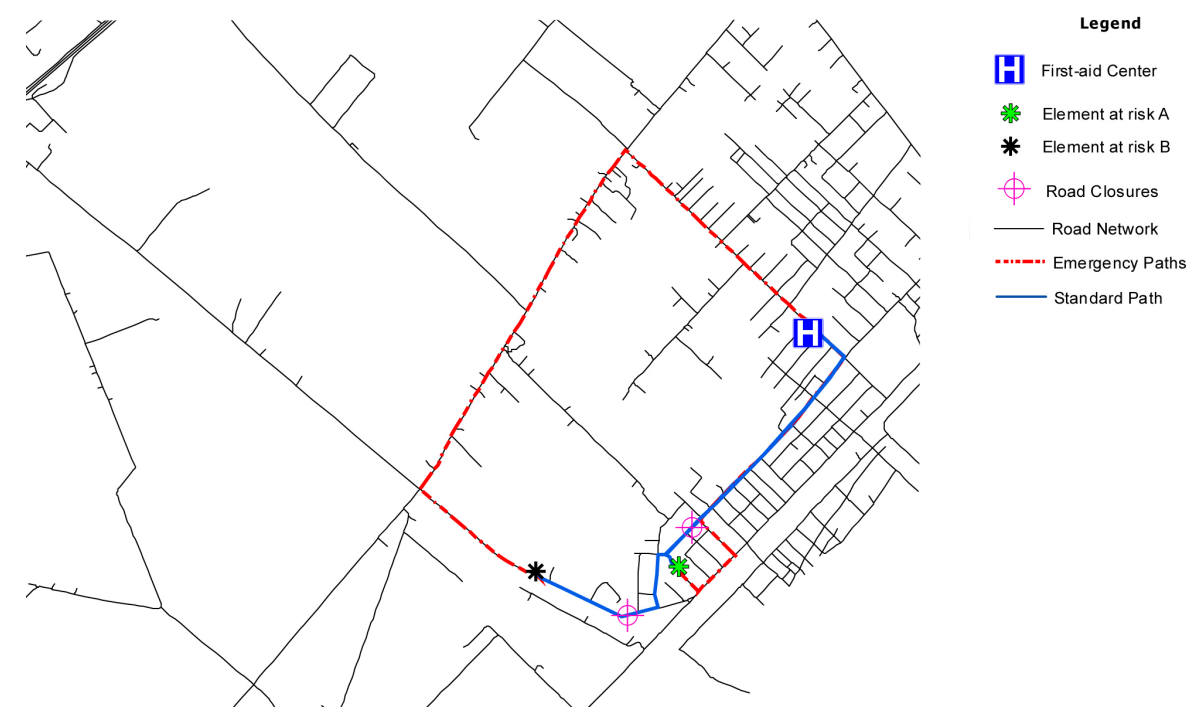

Figure 5. Graphical example of the elements (e.g. standard and emergency shortest paths, origin (i.e. first-aid centre) and destinations (i.e. buildings at risk), and node in which there are road closures) involved in Eqs. (1) and (2).

that requires rescue:

$$
I_{i}=\frac{\sum_{o=1}^{m}\left[\left(1-\frac{P_{s i, o}}{P_{\mathrm{e} i, o}}\right) \cdot \frac{P s_{\max , i}}{P s_{i, o}}\right]}{\sum_{o=1}^{m} \frac{P_{\mathrm{smax}, i}}{P_{s i, o}}} .
$$

The impedance index in Eq. (2) is used to estimate the impedance of nodes (i.e. buildings at risk), i.e. the remoteness derived from measures that aims to identify the buildings that are more difficult to reach by the emergency services. In Fig. 5, the black building has the highest degree of impedance. The inverse (connectivity) reliability index, instead, in Eq. (1) is useful to highlight the strategic paths that connect the elements of the system. The inverse reliability and impedance index ranges between 0 , i.e. no impedance, and 1 , the highest value of inverse reliability or impedance, i.e. where the building is completely isolated.

Considering that each shortest path is composed of a number $(k)$ of arches, an index to estimate the strategic importance of single arches is estimated; it is known as the hierarchy index. A network link is critical if loss or substantial degradation of the link significantly diminishes the accessibility of the network or of particular nodes. Therefore, the arches that are involved in a greater number of path connections (i.e. the ones that could be used more often by aid vehicles to reach the flood-prone areas) are the more important arches for maintenance of the emergency management performance.

The hierarchy index, $H_{a}$, developed in this study represents the number of paths, $P_{\mathrm{s}}$, that connect the relations $o / d$, using the arc $a_{i}$ :

$$
H_{a}=\sum_{o d}\left(k_{a i} / N P_{s o d}\right)
$$

where $k_{a i}$ is the count, $k$, of the times that the shortest paths, $P_{\mathrm{S}}$, used the arch $a_{i}$ to connect the multiple relations $o / d$. $\mathrm{NP}_{s}$ is the number of shortest paths, $P_{\mathrm{s}}$, that connects the multiple relationship $o / d$. The arch that is more utilized by the shortest paths, i.e. the one with highest $k_{a j}$ (e.g. the one in red in Fig. 6), is of significant importance for the system during emergency management because the performance of emergency services can be affected in a significant way by its inoperability. $H_{a}$ can range between 0 and 1 .

The estimation of the hierarchy index can help to identify the arches most affected by infrastructural relations $o / d$ in order to define a hierarchy between the various infrastructure through the identification of those components in which operation and efficiency are fundamental to the maintenance of network connectivity.

Another measure of network performance in flood emergency conditions is the estimation of possible alternatives for each single arch (i.e. the number of outgoing $\operatorname{arcs} a_{i}$ from the $\left.\operatorname{arc} a_{j}\right)$ in the case of a flood event:

$I R_{a}=1-\left[\left(a_{i j s}-a_{i j E}\right) / a_{i j s}\right]$,

where $a_{i j E}$ is the number of outgoing arcs $a_{j}$ from the arc $a_{i}$ that are inoperable due to the flood events, and $a_{i j S}$ is the number of outgoing arcs $a_{j}$ from the arc $a_{i}$ in the normal functioning of the system. The redundancy concept was introduced by Lhomme et al. (2013) but here is modified in order to consider the situation before and after the flood 


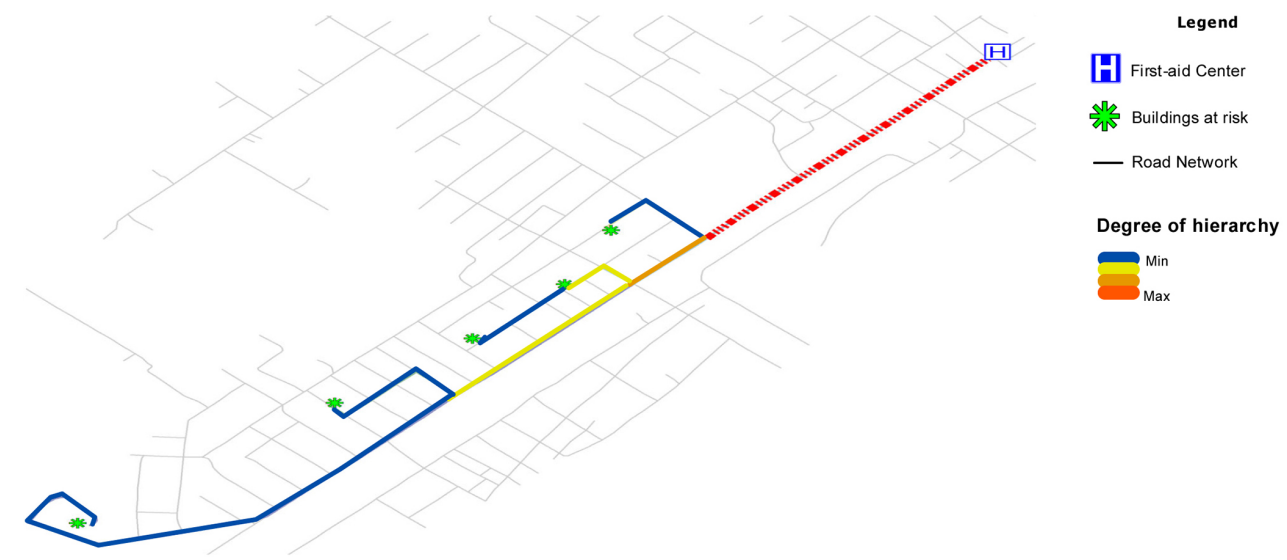

Figure 6. Graphical example of the degree of hierarchy of arches that can be utilized by emergency services during the shortest paths that connect "origin" (e.g. a first-aid centre) with diverse destinations (i.e. the buildings at risk).

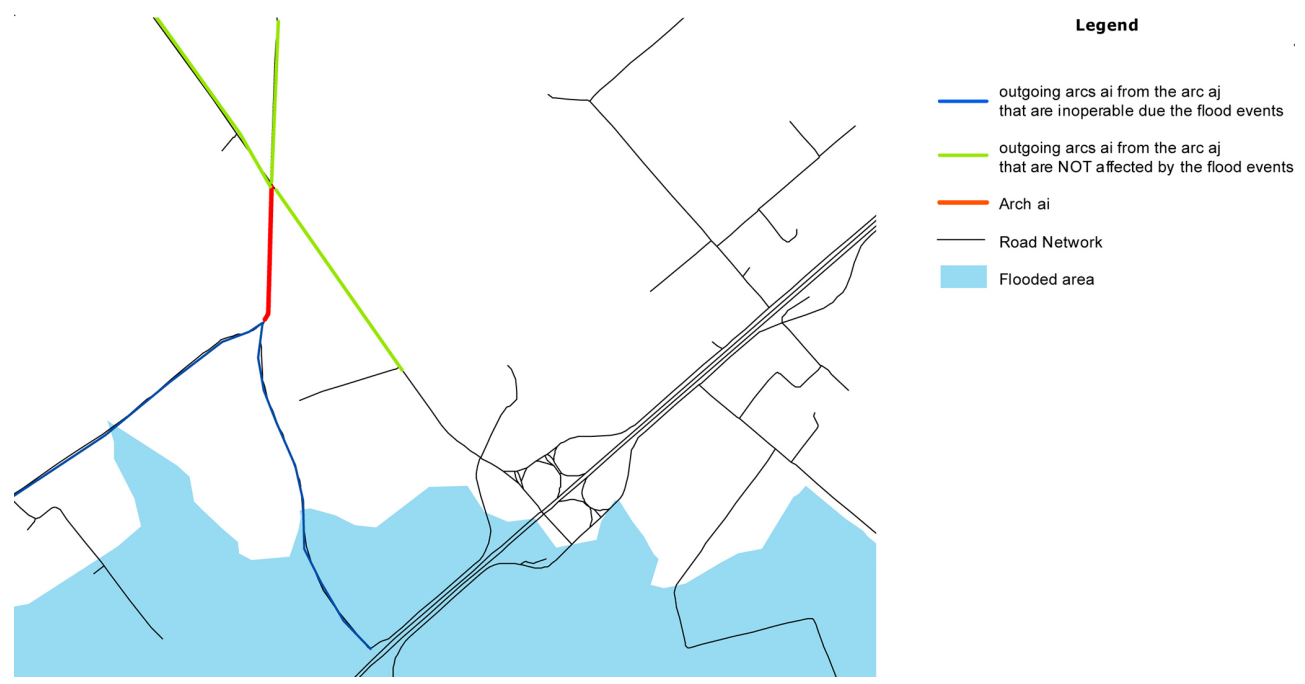

Figure 7. Graphical example of the elements (i.e. $\operatorname{arc} a_{i}$ and its outgoing $\operatorname{arcs} a_{j}$ ) involved in Eq. (4).

event. The inverse redundancy index, which ranges from 0 to 1 , suggests the number of potential alternative connections between arch $a_{j}$ and the others related to that being considered in the emergency phase and, therefore, the number of available and non-available arches, in the case of flooding, that could be utilized by emergency services if the $\operatorname{arc} a_{i}$ is inoperable.

Figure 7 shows an example of parameters involved in Eq. (4): the red line is the $\operatorname{arc} a_{i}$, i.e. the arc to which will be assigned the value of inverse redundancy index; in blue are outgoing $\operatorname{arcs} a_{j}$ from the arc $a_{i}$ that are inoperable due to the flood events; and in green are the arcs $a_{j}$ from the arc $a_{i}$ that are operable even in the case of a flood event. Therefore, the inverse redundancy of arc $a_{i}$ in the system could be affected by the presence of more arcs $a_{j}$ that are inoperable due to the flood events. It means that, in the case of inoperability of $\operatorname{arc} a_{j}$, a great number of outgoing $\operatorname{arcs} a_{i}$ that are also inoperable due the flood event (the blue ones in Fig. 7) will represent a slowing-down in the performance of emergency service that can use less alternatives to the $\operatorname{arc} a_{i}$ during the emergency rescue activities.

Finally, the value of the geometric mean of the product for each arch derived from Eqs. (1), (3), and (4) represents the index of weakness of each arch in the emergency phase:

$x_{i}=\left(\sqrt[3]{R_{a} \cdot H_{a} \cdot I R_{a}}\right)$.

This value, which coupled the flow and functionality approach with the topology analysis, defines a hierarchy between the various arches through the identification of those arches whose operation and performance are fundamental to the maintenance of network connectivity and accessibility in the whole system during a flood emergency. For the structures, i.e. buildings at risk, only Eq. (2) (i.e. the impedance index) is used in order to estimate the weakness index of 
structures at risk for each building. The weakness index, which ranges from 0 to 1 , is reclassified in order to vary in the interval [1-10].

Finally, an influence index for structures and infrastructure is estimated based upon the typology of each building or road in the system during the emergency response phase. It can be defined by a Gaussian curve corresponding to a mathematical function of an exponential type (Pascale et al., 2010):

$$
y_{i}=a \cdot \frac{e^{-\partial \cdot x_{i}^{2.2}}}{\left(1+e^{-\partial \cdot x_{i}^{2.2}}\right)},
$$

where $x_{i}$ is the weakness index of each of the elements previously described; $a$ is a constant which takes on a value equal to 2 and is calculated by fixing the boundary conditions $\left(x_{i}=0\right.$ and $y=0$, where $y=0$ represents $0 \%$ of vulnerability, equivalent to no loss); and $\partial$ is a parameter calculated by fixing boundary conditions as follows: $3<x_{i}<6$ and $3<y<6$ in a condition of medium to high vulnerability and equal to 0.02 (Pascale et al., 2010). The role of this function is to estimate the degree of influence among the elements of the system, considering the degree of connectivity, accessibility, and the role of each in the system in the emergency phase. It can range between 0 and 1 .

Equation (6), as in Pascale et al. (2010), is modified by introducing a correction factor that takes into consideration the population affected by the event, calculated previously in Sect. 2.3.1:

$y_{i}=a \cdot \frac{e^{-\partial \cdot x_{i}^{(2.2+f)}}}{\left(1+e^{-\partial \cdot x_{i}^{(2.2+f)}}\right)}$.

The roads and the buildings at risk located in the census area with higher numbers of population at risk have higher values of the influence index, for the same value of the weakness index and the same functions in the system in the case of an emergency.

The influence index takes into account the role of each element in the system in the emergency phase. In this light, the components such as buildings or communication networks were subdivided into Categories A, B, and C. These elements were divided into these categories relative to the element functions in the systems in the case of an emergency. For instance, if a hospital is damaged, the whole system is affected by an increase in the rescue workload for other forms of assistance. The elements at risk with different roles and importance in the emergency management are set in Categories $\mathrm{A}, \mathrm{B}$, and $\mathrm{C}$. The importance of these features move from Category $\mathrm{A}$ to $\mathrm{C}$ in the following manner:

- Category A includes the most important elements in the case of an emergency, such as hospitals, fire stations, and civil protection stations. These are all elements that give assistance when catastrophic events occur. This category also includes main roads.
- Category B includes all the major socio-economic and environmental elements, such as factories, which can also deal with dangerous materials; large shopping centres; and all other public buildings, including universities, libraries, and churches. All of these can contain a large number of people and can be important from a historical, artistic, and cultural perspective. This category also includes secondary roads.

- Category $\mathrm{C}$ includes private buildings, small business activities, and local roads.

In this study, it is assumed that $\partial$ varies in the interval [0.01-0.1], defining in this way the influence index trend on the basis of the different categories previously described; the parameter $\partial$ assumes a value of $0.06,0.04$, and 0.02 , respectively, for Category A, B, and C, such as in Pascale et al. (2010).

\subsection{Maximum-impact estimation}

Finally, the direct economic consequence estimation is coupled with the indirect systemic impact in emergency management through a maximum-impact index (i.e. phase $\mathrm{V}$ of Fig. 1). The maximum impact of each element within the system is estimated by the equation

$v_{i}=\max \left(y_{i}, s_{i}\right)$,

where $s_{i}$ is the structural damage, estimated by depthdamage curves as described in the previous subsection (phase III of Fig. 1), and $y_{i}$ is the influence of the road network on the elements of the territorial systems. The value of the maximum impact, which can vary in the range $[0,1]$, is the recapitulatory index, and it is also precautionary since it considers the highest value between possible direct and indirect damages. The innovative proposed systemic approach that is integrated in a consequence-estimation model can only increase the value of the damage by taking into account the inoperability of roads or the isolation of buildings due to the flood event.

The model aims to highlight the areas that need priority risk prevention interventions on the basis of accessibility and operability of the structures and infrastructure in the territorial system. In light of this, the estimation of structural damage can be an important indicator of the effectiveness and operability of each element of the system, on the basis of its structural status, and, moreover, the influence index can increase the understanding of decision-making through the estimation of the operability and accessibility in the whole system.

The choice of taking the higher value between the direct and indirect consequences provides the possibility of showing how the impact of a flood hazard on the individual elements, i.e. strategic infrastructure or structure, may support decision-making regarding the prioritization of the risk prevention measures, in the emergency phase of a flood, through 
the estimation of the tendency of a given territorial element to suffer damage of a structural kind and, hence, concerns its intrinsic operability or its influence on the other elements of the system.

\section{Case study}

Ginosa is a city in the Puglia region of Italy, located near the mouth of the Bradano River. The choice of this case study site was justified by the flat morphological characteristics of the river, determined using significant field data collected in recent years as well as the use of high-resolution digital terrain models (DTMs) from laser-scan data. Moreover, the study area includes the mouth of the Bradano River, which is particularly at risk for flooding. This estimation was derived from an analysis of historical data on hydrogeological disasters during the period 1918 to 2000 , conducted as part of the "Affected Italian Areas" by the National Research Council (CNR).

As mentioned, analysis of the data shows that the area at the mouth of the Bradano River has been affected in the past by a significant number of natural disasters. The most recent flood event occurred on 1 March 2011. This flood event was deemed so severe that authorities declared a state of emergency. The flood event of 2011 at the mouth of the Bradano River affected the town in the first days of March when the majority of the hotels, resorts, and tourist attractions were essentially closed or empty. Therefore, in the analysis presented in this case study, seasonal variability in tourist numbers was not taken into account because in March there are very few tourists in this area. This flood event was particularly intense, causing damage to economic activities and residential buildings, as well as provincial and national roads which became unusable due to water and mud. The local administration is still in the process of developing both structural and non-structural measures to cope with flood risk in Ginosa, as well as in the neighbouring towns. Regarding this study, it was deemed preferable to validate the model proposed in this study with an event that has actually occurred, rather than a generic simulated event.

\subsection{Data}

\subsubsection{Characterization of the urban system of Ginosa}

The total population of Ginosa is approximately 22146 (ISTAT, National Institute of Statistics, 2001), with $32 \%$ comprising children under 14 and adults over 65 years of age. The population data are taken from the Italian Institute of Statistics, which stores all the demographical statistics, also in geographical form, for all of Italy ("Geo demo database", available at www.demo.istat.it). The population is aggregated at the census level scale.
The typical building topology is more than $90 \%$ 1-2-floor cottages (SIT Puglia database, 2011). It should be noted that the ISTAT database and Puglia regional databases were developed at different times, resulting in discrepancies between the data. The discrepancies are related to the different times of the acquisition of the population data (ISTAT, National Institute of Statistics, 2001) and the map of the city which represents buildings and roads, at a scale of $1: 5000$ (SIT Puglia database, 2011). These discrepancies are not believed to affect the final results of the model application.

The principal vulnerable hotspots in the Ginosa territorial system are the two most important throughways. These include the "S.S. 106 Jonica Main Road" and the railway "Taranto-Reggio Calabria". In addition, there is a first-aid unit located in the part of the city closer to the sea as well as diverse operative units that could support rescue activities. Several schools, churches, and banks are also identified in the town. The urban area is mainly composed of residential and agricultural areas but also of key resorts, zootechnical activities, and small and medium enterprises (SMEs). More than $45 \%$ of the workers are employed in the service sector, such as in key resorts and hotels located in the area. Seasonal variability of the demography and tourist numbers could have a significant impact in the flood-consequences analysis.

\subsubsection{Hydrological and hydraulic characterization of the simulated scenario}

The flood scenario utilized for the application of the model is a simulated event that has a return time period closer to the real event of 1 March 2011, which occurred in Ginosa, Italy. The maximum discharge of the chosen event can be assimilated to an event with a 30-year return time period, estimated using the VAPI (Valutazioni delle Piene in Italia) method, which is recommended by local authorities (e.g. the Basin Authority of Puglia) in southern Italy (Claps et al., 2005).

Hydraulic simulations of flood scenarios were performed using a 2-D commercial flood model. For this case study, the MIKE FLOOD model was used since it was deemed to be the most appropriate model for this area as highlighted in Sole et al. (2011), who calibrated the model for the study area, using the digital elevation model, which includes cross sections of the river embankment extrapolated from laser scanner data. The friction coefficient of the flooded area was evaluated by the land use map at a scale of $1: 5000$, which is available on the online database of the Puglia region (SIT Puglia database, 2011).

\subsection{Results}

Simulations provided hydraulic characteristics of the chosen flood scenario. Data of water depth, velocity, and wave arrival times were obtained in the urban area.

Due to the flat nature of the flooded zone, the flow velocity was average-low, and the water depth high, in most of 


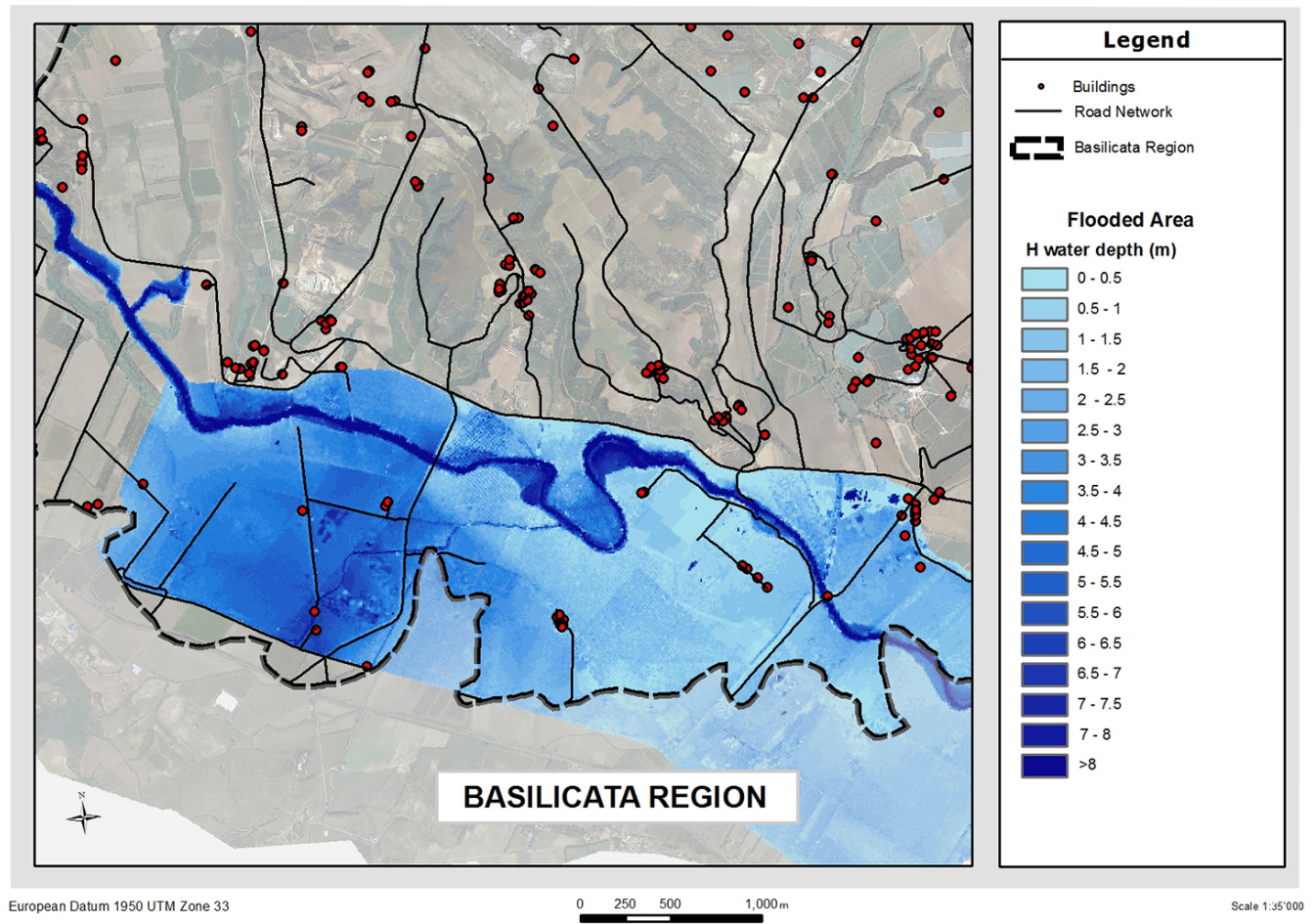

Figure 8. Water depth, $H$, from hydraulic modelling (upflow).

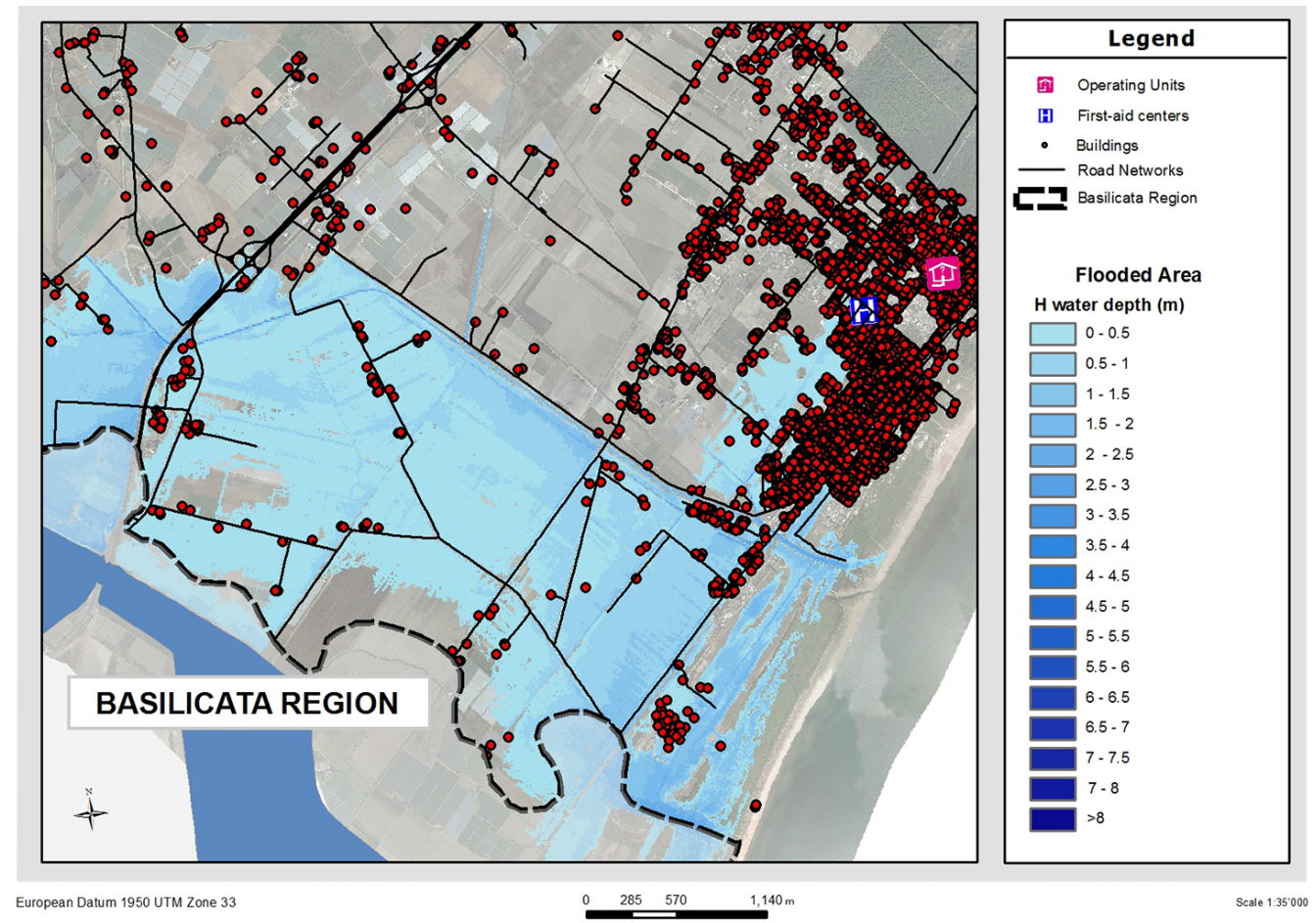

Figure 9. Water depth, $H$, from hydraulic modelling (downflow). 
Table 4. Flooded area for the different categories of water depth, $H$.

\begin{tabular}{lr}
\hline Water depth $(\mathrm{m})$ & Flooded area $\left(\mathrm{m}^{2}\right)$ \\
\hline $0.0-0.5$ & 9707000 \\
$0.5-1.0$ & 7902700 \\
$1.0-1.5$ & 5366700 \\
$1.5-2.0$ & 2692600 \\
$2.0-2.5$ & 1192700 \\
$2.5-3.0$ & 687600 \\
$3.0-3.5$ & 529800 \\
$3.5-4.0$ & 509800 \\
$4.0-4.5$ & 471800 \\
$4.5-5.0$ & 424100 \\
$5.0-5.5$ & 284700 \\
$5.5-6.0$ & 153700 \\
$6.0-6.5$ & 118900 \\
$6.5-7.0$ & 88100 \\
$7.0-7.5$ & 81400 \\
$7.5-8.0$ & 68000 \\
$>8$ & 282300 \\
\hline
\end{tabular}

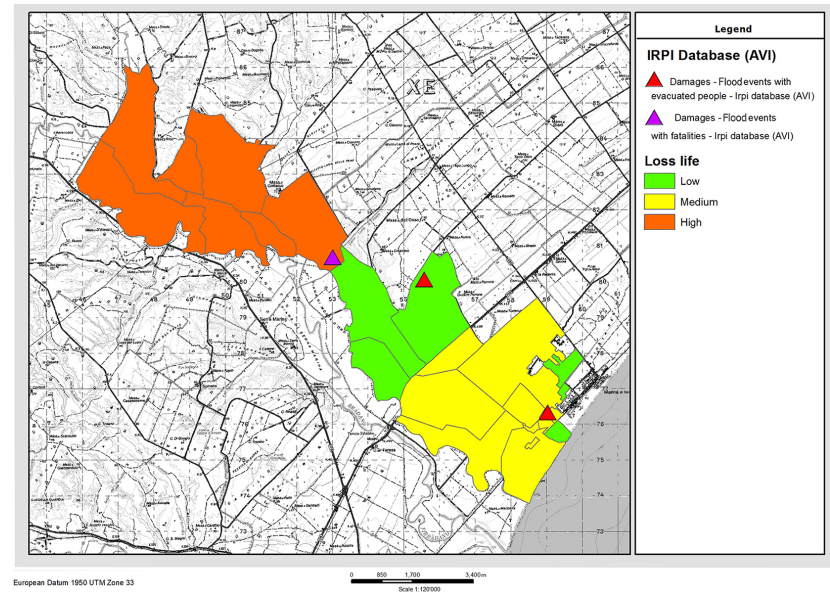

Figure 10. Map of the estimated loss of life divided into categories (low, medium, and high) for the flood event, compared with historical information (AVI project, 2000).

Warning time is defined as the time difference from the firstnotice flow and the first-damage flow. We made the assumption that the first-notice peak corresponded to the time when the first building of Ginosa is affected by the river flow since Ginosa does not have a flood warning system. Additionally, in the literature and on the web there is evidence that there has been no public education on flood risk, risk communication, and recent events have highlighted the lack of coordination between emergency agencies and authorities. Hence, in this case study, the fatality rates considered in the lowest level of flood severity understanding, i.e. category $\mathrm{C} 1$ of Table 2, area applied.

The low value of loss of life estimated by the model is addressed by the fact that, even though there is evidence of a lack of a warning system and public education activity, the peak unit flow rate is really low in the area due to the lower flow velocity estimated by the 2-D numerical flood model.

The total loss of life estimated by the model corresponds to less than one fatality due to the low population density of the area as well as the low percentage of people at risk. In the event of 1 March 2011, there were no reported fatalities but substantial displacement of populations and damage to infrastructure, farms, and resorts, as highlighted in Table 5, which provides information on the direct economic damage, estimated by the model, considering this chosen flood scenario.

After the 1 March event, the total amount of money requested on the basis of a self-estimation by the citizens of Ginosa to the Italian government for the damages to their properties due to this flood event was around EUR 6501741 (source: "Ordinanza ministeriale del 5 luglio 2012 n. 4024"), in comparison to the EUR 4736125 estimated by the model as direct economic damages.

This discrepancy could be justified by the evidence that the model does not take into consideration the damage caused by 
Table 5. Direct economic damage due to the event simulated by the model.

\begin{tabular}{llrrrr}
\hline Occup. type & Description & $\begin{array}{r}\text { Structural } \\
\text { value }(€)\end{array}$ & $\begin{array}{r}\text { Contents' } \\
\text { value }(€)\end{array}$ & $\begin{array}{r}\text { Structural } \\
\text { damage }(€)\end{array}$ & $\begin{array}{r}\text { Contents' } \\
\text { damage }(€)\end{array}$ \\
\hline IND & Zoothecnical activities & 9800000 & 34300000 & 0 & 0 \\
IND & SMEs & 12560000 & 43960000 & 24000 & 84000 \\
ReS1 and RES2 & Residential buildings & 452300000 & 226150000 & 1620000 & 752500 \\
PUB & Public services & 7540000 & 15080000 & 0 & 0 \\
TRN & Main roads & 48516000 & 1940676 & 2528915 & 735294 \\
TRN & Urban roads & 145932500 & 5836807 & 6743983 & 2101124 \\
TRN & Railways & 30694000 & 1534700 & 1098666 & 433887 \\
COM & Hotels and resorts & 19050000 & 38100000 & 928125 & 1327500 \\
FAR & Agricultural areas & 0 & 5999187 & 0 & 5999187 \\
FAR & Forest areas & 0 & 597750 & 0 & 63280 \\
\hline
\end{tabular}

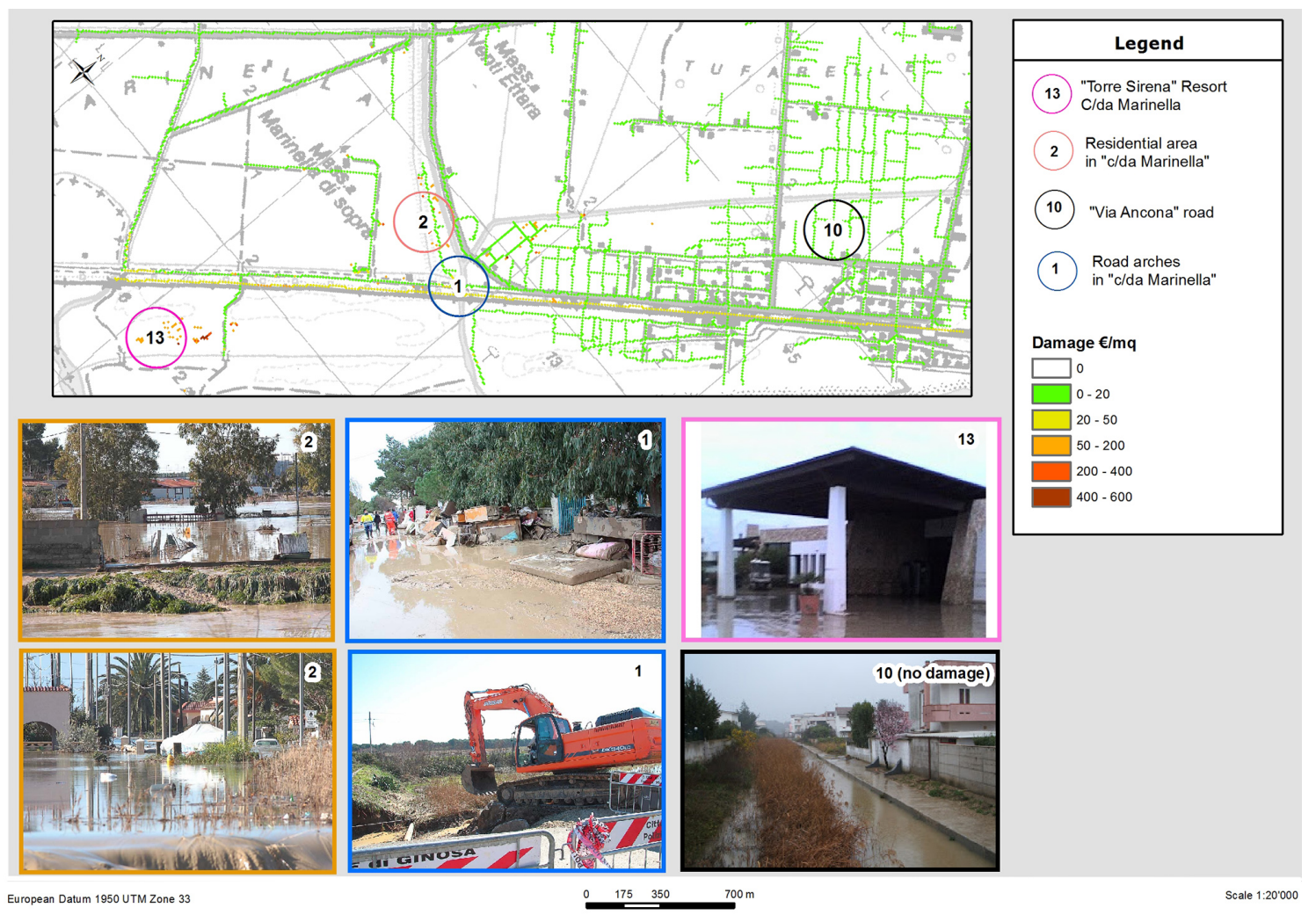

Figure 11. Direct damage estimation.

pluvial contribution to the flood event (the model simulates only the river flood event). Indeed, the number of buildings affected by the flood estimated in the model is about $63 \%$ of the number of buildings affected by the real event (about 1000 buildings). It should be noted that it is not possible to complete a validation on the other elements (i.e. roads, railways, agricultural areas) involved in the flood event due to a lack of available data from the real event. However, it is possible to make a spatial comparison with photos recorded at 10 observation points throughout the city (Figs. 11, 13 and 14 ), as was done in this study.

Figure 11 provides a comparison between the model results and several site surveys by or after the events. It gives an overview of the consequences of the event and the potential reliability of the model. The area in which damage potential is greatest and most affected during the flood event is that closest to the river, where residential buildings and a resort are located in "c/da Marinella". Meanwhile, the area on the far end of the riverbed (i.e. "Via Ancona Road") received 


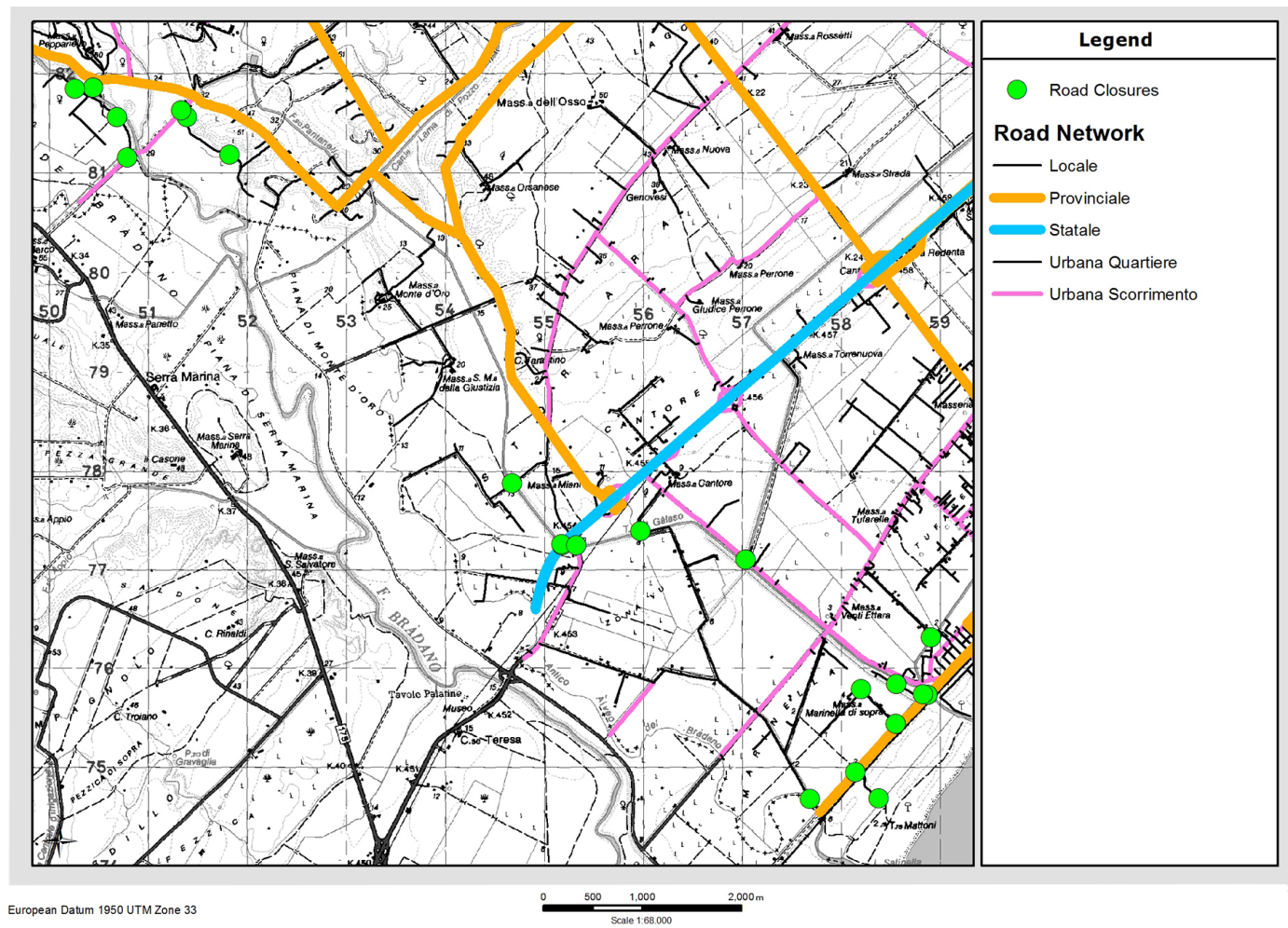

Figure 12. Road closures due the chosen scenario.

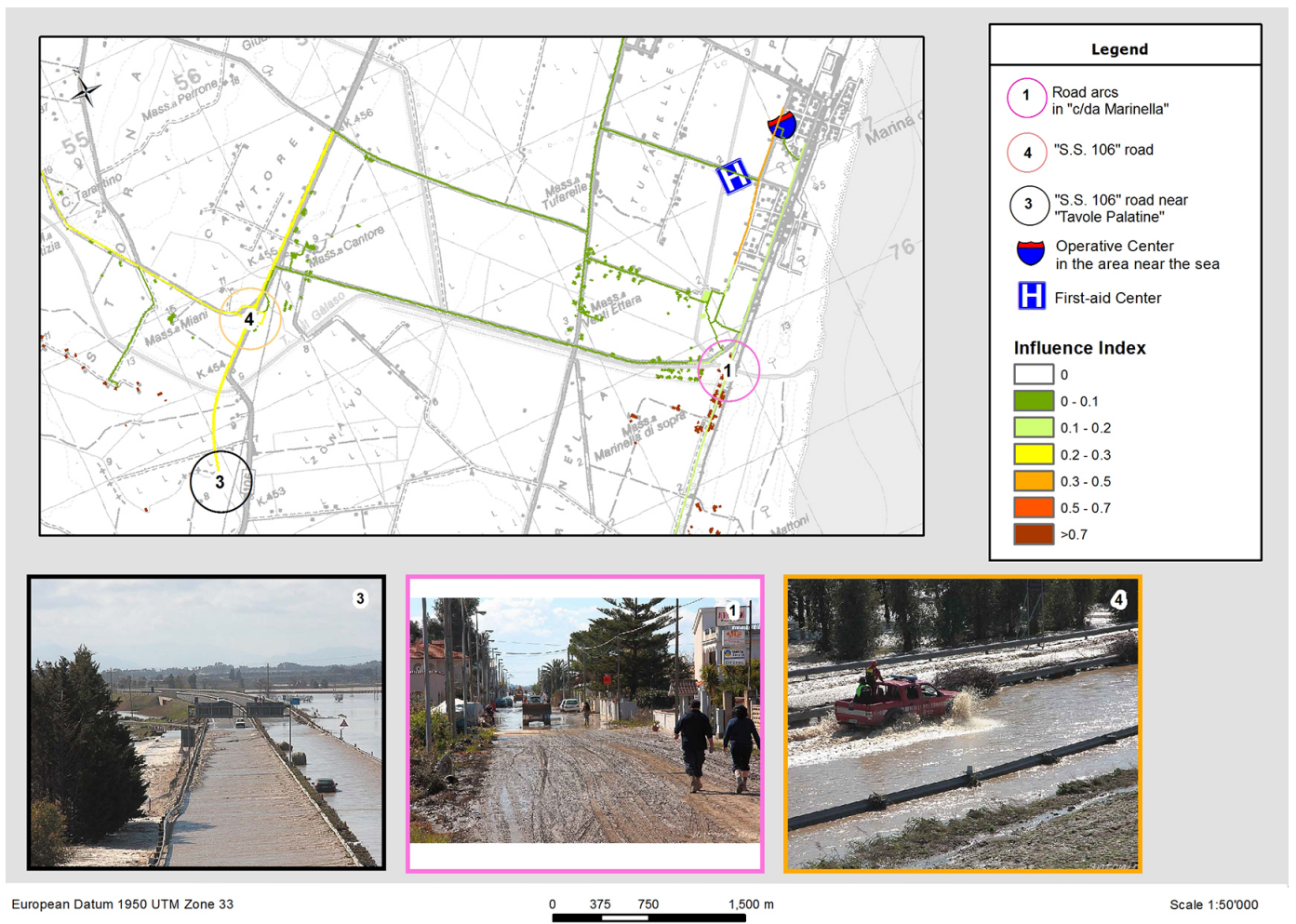

Figure 13. Influence index estimation. 


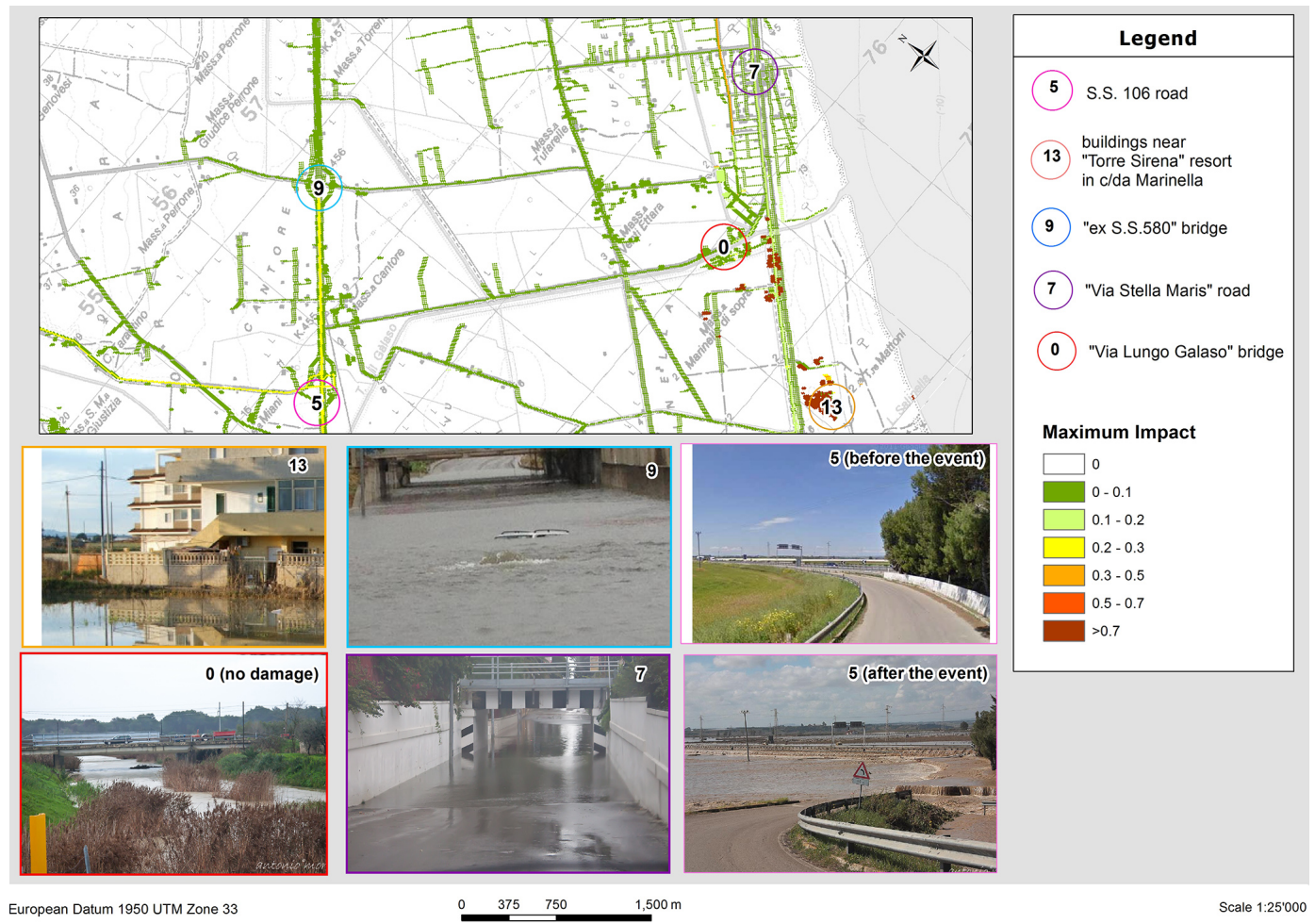

Figure 14. Maximum-impact estimation.

minimal damage (Fig. 11). During the actual flood, the majority of claims from damage associated with the natural disaster came from residents and proprietors of factories and industries closest to the river. Indeed, one of the most damaged buildings was the "Torre Sirena" resort, which resulted in one of the highest values of the influence index because it has a high impedance index (Eq. 2, Sect. 2.4.2).

The flood event of 1 March 2011 also caused serious damage to the main infrastructural systems, as well as indirect damage to most of the surrounding area. Indeed, the failure of some parts of the transport infrastructure would have the most serious effects on access to specific locations and overall system performance. Based on the criteria described earlier, the road closures are illustrated in Fig. 12. This estimation allows for the identification of potential inoperable road arches that could affect the whole system during the emergency response activities.

Figure 13 outlines the potential fragility in connectivity between emergency centres and the flooded area.

Figure 13 shows the S.S. 106 road has a medium value of the influence index and this is justified by the important function that S.S. 106 has in the system: this road is a highway, i.e. a "Strada Statale" in accordance with the Italian road classification, and it is an important connection between the operative centres located in the central part of the city and the buildings at risk located in the area closer to the sea. Figure 13 also shows that the roads closer to the first-aid centre, i.e. the element represented by the blue rectangle with the white " $\mathrm{H}$ ", are coloured in orange, and this means that they have a high value of influence index. This is justified because this road has an elevated value of the hierarchy index (Eq. 3 in Sect. 2.4.2).

Figure 14 illustrates that the maximum-impact estimation is important to identify hotspots such as the main road, S.S. 106 , which is very important because it crosses through the town, dividing it into two parts (e.g. Ginosa Marina located in front of the sea and Ginosa town inland). The neighbouring roads and the main street act as a connection between the area at risk and the middle of the town and beaches. The zone located in c/da Marinella also had a high value for this index because it is almost completely isolated (Fig. 14).

The validations performed by comparisons with the case study illustrate the reliability of the model, which allows for a satisfactory representation of the fragility of the territorial system. It is possible that a similar conclusion could have been obtained simply through expert judgment due to the relative simplicity of the territorial system studied. However, the results we show here can be viewed as important given the reliability of the model adopted and the value of flood emergency management planning.

The proposed model outlined in this paper provides a quantitative estimate of flooding consequences on the basis of direct-impact estimation, i.e. structural and economic loss estimation, and an estimation of loss of life, taking into 
account the operability of the strategic emergency structures, their accessibility, and connection within the urban area during the emergency phase of a flood.

The model can support emergency planning through the definition of a hierarchy among the various structures and infrastructure by identifying those structures and infrastructure whose loss of operability and accessibility could cause vulnerability in the entire system and problems with the performance of rescue activities and victim assistance. In this manner, emergency flood planners can recognize which infrastructure is critical to the maintenance of network connectivity, as well as the structures whose operability and safety are critical during the emergency phase to improve the planning of possible mitigation interventions.

\section{Conclusions}

This paper has presented a new approach to integrate the analysis of an accessibility and operability model for estimation of the strategic elements in the emergency phase associated with a consequence-estimation model during a flood event. The aim is to support decision-making regarding the prioritization of risk prevention measures in order to optimize investments. The innovative aspect of the proposed model is to provide a direct and indirect estimation of flood consequences on the basis of the operability of strategic emergency structures, their accessibility, and connection with the urban system of a city in emergency phases. The accessibility and operability model, illustrated in the GIS model and integrated in the consequence-estimation model, helps to define a hierarchy among the various structures and infrastructure by identifying those structures and infrastructure whose operation and efficiency are fundamental to the maintenance of network connectivity. In this way, the model identifies the structures and infrastructure whose maintenance of performance, in terms of connectivity or operability, could be essential in order to facilitate assistance to victims and rescue activities, and could highlight the areas that need priority interventions. The latter could be extremely useful in cases of limited financial resources.

The proposed model was piloted and validated in an urban area of the Puglia region, southern Italy, to demonstrate its operability for providing planners with a tool to identify the hotspots in the urban system affected by floods and to aid in prioritizing interventions.

Future developments of the proposed model could deal with the analysis of risk, implementing in the model the possibility of simulated diverse flood scenarios characterized by probabilities of occurrence, in order to obtain a probability of the maximum impact of the structure and infrastructure within the system. In addition, the estimation of the economic cost of systemic loss during the emergency phase could provide more information on prioritizing risk mitiga- tion measures in terms of cost-benefit analyses of interventions.

Finally, the integration of local stakeholders in the development and use of the model could assist authorities to facilitate the quality and fairness of flood risk management. Incorporation of diverse stakeholder views can increase the legitimacy of such processes given the significant uncertainty surrounding the impact of climate change and the dynamics of socio-economic systems.

Acknowledgements. We would like to thank three reviewers for their very valuable comments on the first version of this article. Funding for this study was provided, for the contributions of the author belonging to RSE SpA, by the Research Fund for the Italian Electrical System under the contract agreement between RSE $\mathrm{SpA}$ and the Italian Ministry of Economic Development-General Directorate for Nuclear Energy, Renewable Energy, and Energy Efficiency, stipulated on 29 July 2009, in compliance with the decree of 11 November 2012.

Edited by: P. Tarolli

Reviewed by: three anonymous referees

\section{References}

Adikati, Y. and Yoshitani, J.: United Nations World Water Assessment Programme: Global Trends in Water-Related Disasters an insight for policymakers, United Nations Educational, Scientific and Cultural Organization, UNESCO 2009.

Albano, R., Amicarelli, A., Mirauda, D., Agate, G., Sole, A., and Taramasso, A. C.: Experimental validation of a 3-D SPH model for the simulation of a dam-break event involving multiple fixed and mobile bodies, 7th WSEAS International Conference on Engineering Mechanics, Structures, Engineering Geology, Special session "Analysis and modelling of fast-moving flow-like phenomena", Salerno, Italy, June 3-5, 2014.

Apel, H., Aronica, G. T., Kreibich, H. and Thieken, A. H.: Flood risk analyses-how detailed do we need to be?, Nat. Hazards, 49, 79-98, 2009.

AVI ("Aree Vulnerate Italiane") project, inventory of areas affected by landslides and floods in Italy from 1918 to 2000, available at: http://avi.gndci.cnr.it/, Department of Civil Protection to the National Group for Prevention of Hydrological Hazards (GNDCI) of the National Research Council IRPI ("Istituto Nazionale per la Protezione Idrogeologica”), Italy, 2000.

Claps, P. and Fiorentino, M.: Valutazione delle Piene in Italia, Rapporto di sintesi per la regione Basilicata (bacini del versante ionico), GNDCI-CNR. Dipartimento di Ingegneria e Fisica dell'Ambiente, Università della Basilicata-Potenza, 2005.

Dalziell, E. and Nicholson A.: Risk and impact of natural hazards on a road network, J. Transp. Eng.-ASCE, 127, 159-166, 2011.

Defra: Making space for water: developing a new government strategy for flood and coastal erosion risk management in England Department for Environment, Food and Rural Affairs, London, 2004. 
Department of Water Resources Division of Flood Management: Flood Rapid Assessment Model (F-RAM) Development, State of California, The Resources Agency, 2008.

DHS (Department of Homeland Security): Estimating Economic Consequences for Dam Failure Scenarios, Dams Sector, US Department of Homeland Security, September 2011, 2011a.

DHS (Department of Homeland Security): Estimating Loss of Life for Dam Failure Scenarios, Dams Sector, US Department of Homeland Security, September 2011, 2011 b.

Djordjević, S., Butler, D., Gourbesville, P., Mark, O. and Pasche, E.: New policies to deal with climate change and other drivers impacting on resilience to flooding in urban areas: the CORFU approach, Environ. Sci. Pol., 14, 864-873, doi:10.1016/j.envsci.2011.05.008, 2011.

Escuder-Bueno, I., Morales Torres, A., Castillo Rodriguez, J. T., and Momparler, S. P.: 2nd ERA-NET CRUE Research Funding Initiative Flood resilient communities - managing the consequences of flooding Methodology for pluvial and river flooding risk assessment in urban areas to inform decision-making, Report July 2011.

Escuder-Bueno, I., Castillo-Rodríguez, J. T., Zechner, S., Jöbstl, C., Perales-Momparler, S., and Petaccia, G.: A quantitative flood risk analysis methodology for urban areas with integration of social research data, Nat. Hazards Earth Syst. Sci., 12, 2843-2863, doi:10.5194/nhess-12-2843-2012, 2012.

FEMA (Federal Emergency Management Agency): HAZUSMH Technical Manual. Washington, DC, FEMA, Department of Homeland, Technical Report, 2003.

Franchin, P., Lupoi, A. and Pinto, P.-E.: On the role of road networks in reducing human losses after earthquakes, J. Earthq. Eng., 10, 195-206, 2006.

Graham, W. J.: A procedure for estimating loss of life caused by dam failure, DSO-99-06, US Department of Interior, Bureau of Reclamation, 1999.

Gruntfest, E.: Flash floods in the United States, in: Storms, edited by: Pielke, J. R. and Pielke, S. R., Routledge, London, 192-206, 2000.

Gruntfest, E., and Ripps, A.: Flash floods: warning and mitigation efforts and prospects, in: Floods, 1, edited by: Parker, D., Routledge, London, 377-390, 2000.

International Strategy for Disaster Reduction (ISDR): United Nation, Living with risk: A global review of disaster reduction initiative, Volume II Annexes, 2004.

ISTAT, National Institute of Statistics: i dati geografici delle basi territoriali, available at: http://www.istat.it/it/strumenti/cartografia (last access: October 2013), 2001.

Jha, A. K., Bloch, R., and Lamond, J.: Cities and flooding: a guide to integrated urban flood risk management for the 21st century, World Bank Publications, 2012.

Jonkman, S. N.: Global perspectives of loss of human life caused by floods, Nat. Hazards, 34, 151-175, 2005.

Klijn, F., Baan, P., De Bruijn, K. M., and Kwadijk, J.: Overstromingsrisico's in Nederland in eenveranderend klimaat: verwachtingen, schattingen en berekeningen voor het project Nederland Later, WL Delft Hydraulics report Q4290.00, 2007 (in Dutch).
Lhomme, S., Serre, D., Diab, Y., and Laganier, R.: Analyzing resilience of urban networks: a preliminary step towards more flood resilient cities, Nat. Hazards Earth Syst. Sci., 13, 221-230, doi:10.5194/nhess-13-221-2013, 2013.

Luino F., Chiarle M., Nigerelli G., Agangi A., Biddoccu M., Cirio C. G. and Giulietto W: A model for estimating flood damage in Italy, in: Preliminary results, Proceedings of Environmental Economics and Investment Assessment, edited by: Aravossis, K., Karakas, E., Brebbia, C. A., and Kungolos, A., 65-74, 2006.

Menoni S., Peergalani F., Boni M. P., and Pertini V.: Lifelines earthquake vulnerability assessment: a systemic approach, Soil Dynam. Earthq. Eng., 22, 9-12, doi:10.1016/S02677261(02)00148-3, 2002.

Merz, B., Kreibich, H., Schwarze, R., and Thieken, A.: Review article "Assessment of economic flood damage", Nat. Hazards Earth Syst. Sci., 10, 1697-1724, doi:10.5194/nhess-10-16972010, 2010.

Meyer, V., Becker, N., Markantonis, V., Schwarze, R., van den Bergh, J. C. J. M., Bouwer, L. M., Bubeck, P., Ciavola, P., Genovese, E., Green, C., Hallegatte, S., Kreibich, H., Lequeux, Q., Logar, I., Papyrakis, E., Pfurtscheller, C., Poussin, J., Przyluski, V., Thieken, A. H., and Viavattene, C.: Review article: Assessing the costs of natural hazards - state of the art and knowledge gaps, Nat. Hazards Earth Syst. Sci., 13, 1351-1373, doi:10.5194/nhess-13-1351-2013, 2013.

ODPM: Preparing for floods, Office of the Deputy Prime Minister, London, 2002.

Ordinanza ministeriale del 5 luglio 2012 no. 4024 - Presidenza Consiglio dei Ministri, 2012.

Pascale, S., Sdao, F., and Sole, A.: A model for assessing the systemic vulnerability in landslide prone areas, Nat. Hazards Earth Syst. Sci., 10, 1575-1590, doi:10.5194/nhess-10-15752010, 2010.

Penning-Rowsell, E., Johnson, C., Tunstall, S., Tapsell, S., Morris, J., Chatterton, J. and Green, C.: The Benefits of Flood and Coastal Risk Management: A Handbook of Assessment. Techniques, London, Middlesex University Press, 2005.

Sayers, P., Li, Y., Galloway, G., Penning-Rowsell, E., Shen, F., Wen, K., Chen, Y., and Le Quesne, T.: Flood Risk Management: A Strategic Approach. Paris, UNESCO, 2013.

Scawthorn, C., Flores, P., Blais, N., Seligson, H., Tate, E., Chang, S., Mifflin, E., Thomas, W., Murphy, J., Jones, C. and Lawrence, M.: HAZUS-MH flood loss estimation methodology, II, Damage and loss assessment, Nat. Hazards Rev., 7, 72-81, 2006.

Sdao, F., Albano, R., Sivertun, A., Sole, A., Pascale, F., Giosa, L.: Chapter 19: Model of Systemic Vulnerability Assessment in Urbanized Areas Exposed to Combined Risk of Landslide and Flood, in: Geographic Information Analysis for Sustainable Development and Economic Planning: New Technologies, edited by: Borruso, G., Bertazzon, S., Favretto, A., Murgante, B., Torre, C. M., IGI Global, 274-294, doi:10.4018/978-1-46661924-1.ch019, 2013.

SIT PUIGLIA, Banche dati territoriali della Regione Puglia, Geoportal and opendata of Puglia Region, available at: http://www. sit.puglia.it (last access: October 2013), 2011. 
Sole, A., Giosa, L., Cantisani, A., Statuto, D., and Nolè, L.: Analisi di sensibilità nella modellazione delle inondazioni di aree pianeggianti, J. Eng. Geol. Environ., 1,157-167, doi:10.4408/IJEGE.2011-01.S-08, 2011.

Taylor, M. A. P., Sekhar, S. V. C., and D'Este, G. M.: Application of Accessibility Based Methods for Vulnerability Analysis of Strategic Road Networks, Netw. Spat. Econ. 6, 267-291, 2006.
Teo, F. Y., Xia, J., Falconer, R. A., and Lin, B.: Experimental study on the interaction between vehicles and floodplain flows, Int. Ser. Prog. Wat. Res., 10, 149-160, 2012.

Vorogushyn, S., Lindenschmidt, K.-E., Kreibich, H., Apel, H., and Merz, B.: Analysis of a detention basin impact on dike failure probabilities and flood risk for a channel-dike-floodplain system along the river Elbe, Germany, J. Hydrol., 436-437, 120-131, 2012. 